\title{
Correction to: the Effect of Cross-Linking Efficiency of Drug-Loaded Novel Freeze Gelated Chitosan Templates for Periodontal Tissue Regeneration
}

\author{
Syed Saad B. Qasim, ${ }^{1,2,5}$ (D) Liebert Parreiras Nogueira, ${ }^{1}$ Amr S. Fawzy, ${ }^{3}$ and Umer Daood ${ }^{4}$
}

Published online 1 September 2020

\section{Correction to: AAPS PharmSciTech (2020) 21: 173 \\ https://doi.org/10.1208/s12249-020-01708-x}

The correct spelling of the second author's name is Liebert Parreiras Nogueira.

Publisher's Note Springer Nature remains neutral with regard to jurisdictional claims in published maps and institutional affiliations.

The online version of the original article can be found at https:// doi.org/10.1208/s12249-020-01708-x

\footnotetext{
${ }^{1}$ Department of Biomaterials, Institute of Clinical Dentistry, University of Oslo, Oslo, Norway.

${ }^{2}$ Department of Bioclinical Sciences, Faculty of Dentistry, Kuwait University, PO-Box 24923, 11310, Safat, Kuwait.

${ }^{3}$ UWA Dental School, University of Western Australia, 17 MonashAvenue, Nedlands, WA 6009, Australia.

${ }^{4}$ Clinical Dentistry Division, Restorative Division, School of Dentistry, International Medical University Kuala Lumpur, 126, JalanJalil Perkasa 19, Bukit Jalil 57000, Kuala Lumpur, Wilayah Persekutuan, Malaysia.

${ }^{5}$ To whom correspondence should be addressed. (e-mail: ssbqasim@odont.uio.no)
} 